\title{
Dermatofibrosarcoma protuberans of male breast: a
}

\section{case report}

\begin{abstract}
Dermatofibrosarcoma (DFSP) of breast is a rare tumour that usually affects young and middle aged adults. Its occurrence in the breast is rare phenomenon and in male is even rarer. We describe a case of 48-year-old male with nodular swelling on the left breast.
\end{abstract}

Keywords: dermatofibrosarcoma protuberance, male, breast
Volume 6 Issue 4 - 2018

\author{
Dhakal R,' Makaju R,' Makaju S, ${ }^{2}$ Shrestha G \\ 'Department of Pathology, Kathmandu University School of \\ Medical Sciences, Nepal \\ ${ }^{2}$ Department of Surgery, Kathmandu University School of \\ Medical Sciences, Nepal \\ ${ }^{3}$ Department of Pathology, Patan Academy of Health Sciences, \\ Nepal
}

Correspondence: Dr. Rachana Dhakal, Assistant Professor , Department of Pathology, Kathmandu University School of Medical Sciences, Dhulikhel, Kavre, Nepal, Tel 984I777944,

Received: July 1I, 2016 | Published: July 18, 2018

\section{Introduction}

Dermatofibrosarcoma protuberans (DFSP) is an uncommon tumour of skin that accounts for $1.8 \%$ of all skin tumours. ${ }^{1}$ The tumour occurs on any part of the body but are commonly found at the trunk and extremities. ${ }^{2}$ It usually affects adults between the second and fifth decade of life. Incomplete resection can lead to local recurrence but distant metastases are rare., ${ }^{3,4}$ Immunohistochemistry remains an important tool to categorize DFSP. CD 34 is a better indicator. Besides, Factor xiiia, and apo-d also remains some other diagnostic tools. ${ }^{5}$

\section{Case report}

A 48-year-old male presented with swelling on the left breast. On examination, there was a nodular swelling about $13 \times 10 \times 5 \mathrm{~cm}$ in size. It was non-tender and freely mobile over the pectoralis muscle. There was no discharge from nipple and no palpable axillary nodes. The fine needle aspiration cytology (FNAC) report was inconclusive. All the routine blood parameters and chest X-ray were normal. A wide local excision was done. Grossly, specimen consists of grey white nodular tissue bit measuring $13 \times 10 \times 5 \mathrm{~cm}$ (Figure 1). Histopathologically, the slide showed storiform arrangement of tumour cells with uniform population of fusiform or spindle shaped cells with little variation in shape and size with scant cytoplasm (Figure 2) (Figure 3). Immunohistochemistry was done which showed positivity for CD34 (Figure 4).

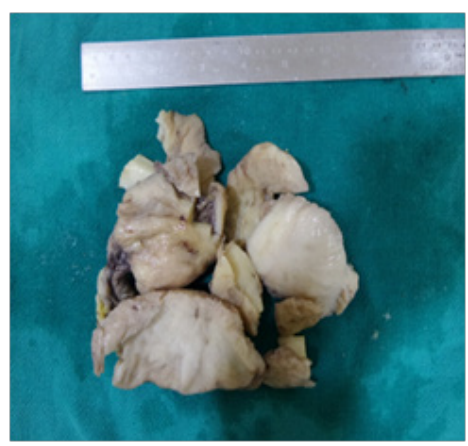

Figure I Grey white tissue.

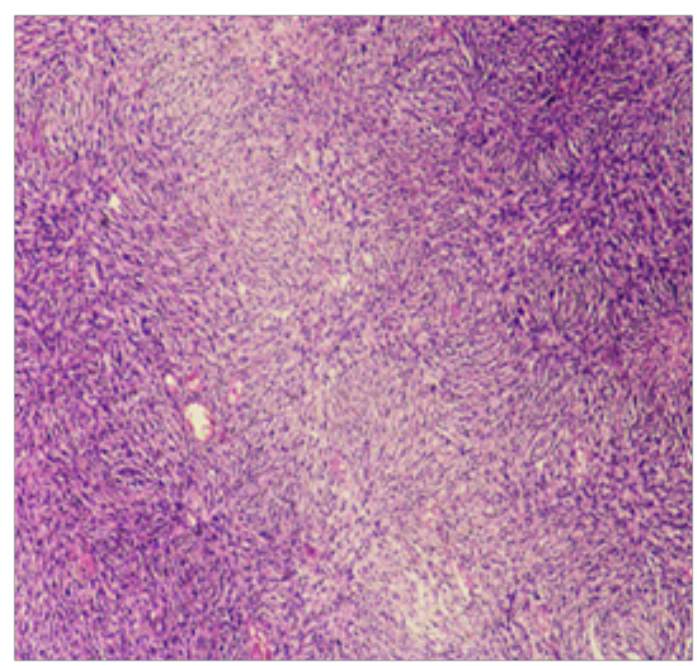

Figure 2 Storiform arrangement of tumour cells $(X \mid 0)$.

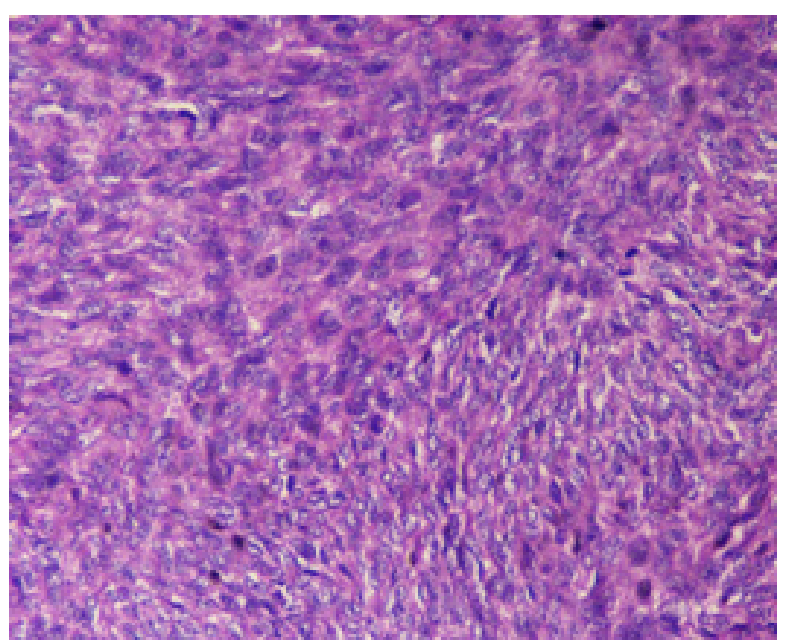

Figure 3 Uniform population of fusiform (X40). 


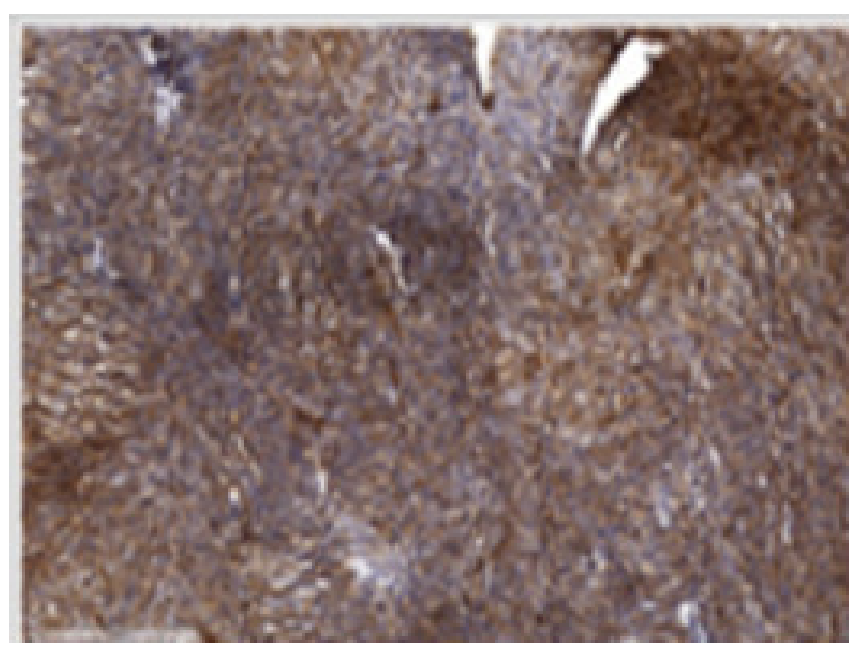

Figure 4 CD34 positive or spindle shaped cells.

\section{Discussion}

In 1890, Taylor first described DFSP. ${ }^{6}$ In 1924, Darier and Ferrand described as a gradual and recurrent cutaneous neoplasm. ${ }^{7}$ In 1925, Hoffman termed "dermatofibrosarcoma protuberans". ${ }^{8}$ It is a low degree malignant soft tissue tumor which arises in the dermis and then spreads into the subcutaneous tissues and muscle. ${ }^{9}$ DFSP is usually less than $5 \mathrm{~cm}$ in size. ${ }^{10}$ The trunk and extremities are the most common sites of involvement which accounts for $85 \%$ of all cases. ${ }^{2}$ Males are more commonly affected than females and the male-to female ratio is approximately $3: 2$. The tumor occurs in patients of all ages, with the highest frequency occurring in the fourth decade of life. ${ }^{6,11}$

DFSP presents as a single, raised, red to bluish, firm cutaneous nodule or plaque with surrounding discoloration. ${ }^{12}$ It is usually painless and indurated, but is extremely infiltrative and has a locally destructive growth that can invade the underlying structure such as fascia, muscles or bones. ${ }^{1,13-15}$

Histopathology reveals relatively uniform densely grouped fusiform cells, with elongated nuclei without significant cytologic atypia or pleomorphism in characteristic storiform arrangement. ${ }^{16}$ Immunohistochemical findings are positivity to CD34 in $84-100 \%$ and to vimentin and negativity to other markers such as S-100, HMB45, desmin and actin. ${ }^{1,3,17,18}$ CD34 positivity is seen in different variants of soft tissue tumour. However, morphological pattern followed by immunohistochemical marker plays a significant role in differentiating DFSP from other tumours with CD34 positivity.

The Mohs micrographic surgery is used as a first-line therapeutic measure in cases of limited tumors for tissue preservation and reduction of recurrence rate..$^{19-22}$

The standard treatment of DFSP is wide local surgical resection with recommended surgical margins of $2-3 \mathrm{~cm}$ including skin, subcutaneous tissue and underlying fascia. ${ }^{23-25}$ The local recurrence rate decreases with the increase of surgical margins. ${ }^{26}$ The factors associated with high rates of recurrence are histological subtype, cellularity, size, location on the head and neck, and high mitotic rate $.26,27$
DFSP is considered as one of the radiosensitive tumors. In the cases with questionable or positive surgical margin, postoperative radiotherapy reduces the risk of local recurrence margins. ${ }^{28,29}$ Radiotherapy is indicated when there is incomplete resection. ${ }^{28,30} \mathrm{It}$ also reduces the morbidity or functional impairment associated with extensive resection.

\section{Conclusion}

Dermatofibrosarcoma protuberans is a rare soft tissue sarcoma. Its occurrence in the breast is even rarer. Mammography and magnetic resonance imaging can help in characterizing the lesion and localizing the lesion for further diagnostic evaluation and surgical planning.

\section{Acknowledgements}

None.

\section{Conflict of interest}

The author declares no conflicts

\section{References}

1. Mendenhall WM, Zlotecki RA, Scarborough MT. Dermatofibrosarcoma protuberans. Cancer. 2004;101(11):2503-2508.

2. Enzinger FM, Weiss SW. From fibrohistiocytic tumours of intermediate malignancy. Soft tissue tumour 2. 1988:252-268.

3. Bhambri S, Desai A, Del Rosso JQ, et al. Dermatofibrosarcoma protuberans: a case report and review of the literature. J Clin Aesthet Dermatol. 2008;1(1):34-36.

4. Gloster HM. Dermatofibrosarcoma protuberans. J Am Acad Dermatol. 1996;35(3 pt 1):355-374.

5. Cottier O, Fiche M, Meuwly JY, et al. Dermatofibrosarcoma presenting as a nodule in the breast of a 75-year old woman: A case report. $J$ Med Case Rep. 2011;5:503.

6. Simon MP, Navarro M, Roux D, et al. Structural and functional analysis of a chimeric protein COL1A1-PDGFB generated by the translocation $\mathrm{t}(17 ; 22)(\mathrm{q} 22 ; \mathrm{q} 13.1)$ in dermatofibrosarcoma protuberans (DP). Oncogene. 2001;20(23):2965-752.

7. Darier S, Ferrand M. Dermatofibrosarcomes progressives etricidivantes on fibrosarcomes de la peau. Ann Dermatol Venereol. 1924;5:545-562.

8. Hoffmann E. Ueber das knollentribendeFibrosarkom der Haunt (dermatofibrosarcomaprotuberans). Dermatol Z. 1925;43:1-28.

9. Ransdorf MJ, Meis-Kindblom JM. Dermatofibrosarcoma protuberans:radiologic appearance. AJR. 1994;163:391-394.

10. Bowne WB, Antonescu CR, Leung DH, et al. Dermatofibrosarcoma protuberans. A clinicopathologic analysis of patients treated and followed at a single institution. Cancer. 2000;88(12):2711-2720.

11. Abenoza P, Lillemoe T. CD34 and VIIIa in the differential diagnosis of dermofibroma and dermatofibrosarcoma protuberans. Am J Demapathol. 1993;15(5):429-434.

12. Wacker J, Khan-Durani B, Hartschuh W. Modified mohs micrographic surgery in the therapy of dermatofibrosarcoma protuberans: analysis of 22 patients. Ann Surg Oncol. 2004;11(4):438-444.

13. Brabant B, Revol M, Vergote T, et al. Dermatofibrosarcoma protuberans of the chest and the shoulder: wide and deep excisions with immediate reconstruction. Plast Reconstr Surg. 1993;92(3):459-462. 
14. Arnaud EJ, Perrault M, Revol M, et al. Surgical treatment of dermatofibrosarcoma protuberans. Plast Reconstr Surg. 1997;100(4):884-895.

15. Lemm D, Mugge LO, Mentzel T, et al. Current treatment options in dermatofibrosarcoma protuberans. J Cancer Res Clin Oncol. 2009;135(5):653665 .

16. Labonte S, Hanna W, Bandarchi-Chamkhaleh B. A study of CD117 expression in dermatofibrosarcoma protuberans and cellular dermatofibroma. J Cutan Pathol. 2007;34(11):857-860.

17. Pérez OG, Righetti R, Woscoff A, et al. Case for diagnosis. Dermatofibrosarcoma protuberans. An Bras Dermatol. 2010;85(2):245247.

18. Adler N, Tsabari C, Sulkes J, et al. Cyclooxygenase-2 expression in dermatofibroma and dermatofibrosarcoma protuberans. J Cutan Pathol. 2008;35(6):532-535.

19. Rutkowski P, Wozniak A, Switaj T. Advances in molecular characterization and targeted therapy in dermatofibrosarcoma protuberans. Sarcoma. 2011:959132.

20. Snow SN, Gordon EM, Larson PO, et al. Dermatofibrosarcoma protuberans: a report on 29 patients treated by Mohs micrographic surgery with longterm follow-up and review of the literature. Cancer. 2004;101(1):28-38.

21. Xiang Q, Lu W, He X, et al. Surgical treatment of dermatofibrosarcoma protuberans using wide local excision combined with Mohs micrographic surgery. Zhongguo Xiu Fu Chong Jian Wai Ke Za Zhi. 2011;25(11):13501353.

22. Galimberti G, Montaño AP, Kowalczuk A, et al. Outcomes in 11 patients with dermatofibrosarcoma protuberans treated with Mohs micrographic surgery. Int J Dermatol. 2012;51(1):89-93.
23. Dragoumis DM, Katsohi LA, Amplianitis IK, et al. Late local recurrence of dermatofibrosarcoma protuberans in the skin of female breast. World $J$ Surg Oncol. 2010;8:48.

24. Chang CK, Jacobs IA, Salti GI. Outcomes of surgery for dermatofibrosarcoma protuberans. Eur J Surg Oncol. 2004;30(3):341-345.

25. Kimmel Z, Ratner D, Kim JY, et al. Peripheral excision margins for dermatofibrosarcoma protuberans: a meta-analysis of spatial data. Ann Surg Oncol. 2007;14(7):2113-2120.

26. Du Bay D, Cimmino V, Lowe L, et al. Low recurrence rate after surgery for dermatofibrosarcoma protuberans: a multidisciplinary approach from a single institution. Cancer. 2004;100(5):1008-1016.

27. Goldblum JR, Tuthill RJ. CD34 and factor-XIIIa immunoreactivity in dermatofibrosarcoma protuberans and dermatofibroma. $\mathrm{Am} J$ Dermatopathol. 1997;19(2):147-153.

28. Sun LM, Wang CJ, Huang CC, et al. Dermatofibrosarcoma protuberans:treatment results of 35 cases. Radiother Oncol. 2000;57(2):175-181.

29. Dagan R, Morris CG, Zlotecki RA, et al. Radiotherapy in the treatment of dermatofibrosarcoma protuberans. Am J Clin Oncol. 2005;28(6):537-539.

30. Lindner NJ, Scarborough MT, Powell GJ, et al. Revision surgery in dermatofibrosarcoma protuberans of the trunk and extremities. Eur J Surg Oncol. 1999;25(4):392-397. 